\title{
A Comparative Study on Adjustment between Obese and Non Obese Children
}

\author{
Rima Sen ${ }^{1 *}$, Dr. Debomita Sikdar ${ }^{2}$
}

\section{ABSTRACT}

We conducted a study on adjustment between obese and non-obese children. We used Adjustment Inventory for School Students (AISS) by A.K.P.Sinha and R.P.Singh and information schedule for collecting information regarding their physical activity, dietary patterns, lifestyle, etc. Results revealed that there has been a significant difference in the emotional, social and educational adjustment between obese and non-obese children. The mean value of different dimensions of adjustment of non-obese children is higher than obese children. The correlation value indicated a significant relationship between the scores of BMI and adjustment. Thus good health status, healthy diet, regular exercise, and physical activities have positive effects on adjustment of children. It may be concluded that healthy life style patterns may prevent obesity amongst children.

Keywords: Obesity, Body Mass Index, Emotional, Social and Educational Adjustment.

Obesity is one of the most common chronic disorders in childhood and its prevalence to increase rapidly. There is a growing awareness of the long term health complications of obesity in children and adolescence. The most wide spread consequences of childhood obesity may be psychosocial. Obese children and adolescence are at risk for psychological and social adjustment problems including lower perceived competences normative sample on social, athletic and appearance domains as well as overall self worth.

A recent research has found alarming facts about childhood obesity. Almost $16-30 \%$ of the children in the age group between 6 to 16 years are obese worldwide. These figures have dramatically increased in the last two decades. Expectedly, $70 \%$ of these children will grow into obese adults. The common triggers of obesity are consumption of high calorie food, inadequate exercise, some hormonal imbalances and child born to obese parents (Lhila, S. 2015).

\footnotetext{
${ }^{1}$ Research Scholar, Department of Home Science, University of Calcutta

${ }^{2}$ Assistant Professor, Department of Home Science, University of Calcutta

*Responding Author

(C) 2016 I R Sen, D Sikdar; licensee IJIP. This is an Open Access Research distributed under the terms of the Creative Commons Attribution License (http://creativecommons.org/licenses/by/2.0), which permits unrestricted use, distribution, and reproduction in any Medium, provided the original work is properly cited.
} 


\section{A Comparative Study on Adjustment between Obese and Non Obese Children}

There is still substantial disagreement concerning the psychological consequences of childhood obesity. Lerner (1972, 1973; Lerner \& Pool, 1972) provided a theoretical framework for the understanding of the relationship between physical appearances and psychosocial functioning and suggested that people differentially attribute psychosocial traits to body types and that the individual's self-perception may be influenced by these appearance-based stereotypes. Baum and Forehand (1984) tested Lerner's model and focused on differences in social interactions among obese and non-obese children: Overweight children received more negative peer reactions. Strauss et al. (1985) replicated this study.

Storch et al. (2004) examined the relationships between physical activities, peer victimization for overweight and overweight youth and children. Participants (child and parent) completed measures on peer victimization, depression, anxiety, social physique anxiety, loneliness and physical activity and both internalizing and externalizing behaviours. Results showed peer victimization was positively correlated to depression, anxiety, social physique anxiety, loneliness etc. Peer victimization was negatively related to physical activity and depressive symptoms and loneliness mediated the relationship between peer victimization and physical activity.

There are several reasons why peer victimization may be a frequent experience in the life of obese children. First, obese children may be labelled as "unattractive" or different, providing bullies with a rationale to victimize. Second, obese children may be hesitant or unable to participate in school activities or interact with peers due to a fear of rejection or physical limitations, which, subsequently, may lead to a smaller social network of friends. Additionally, physical limitations, medical issues, and fewer friends may contribute to the development of social anxiety and low self-esteem. These factors make obese children prime candidates for peer victimization (Storch et al., 2004).

Besides obesity being a risk factor for peer victimization, it may also impact obese children's desire to participate in physical activities. For example, obese, victimized children may avoid physical activity that is not closely monitored (i.e., physical education classes or after-school sports) due to the frequency of peer victimization occurring during these events (Frey et al., 2005). Additionally, peer victimization of obese children may reduce intrinsic motivation for physical activity due to fear of peer victimization during activities (Faith, Leone, Moonseong, \& Pietrobelli, 2002) whereas there is evidence that weight-based peer victimization may lead to negative attitudes about sports and reduced amounts of physical activity (Faith et al., 2002).

Obesity has a negative effect on many children. It affects emotional and psychological health through bullying, low self-esteem and exclusion from opportunities for social interaction. This in turn may lead to poorer levels of educational attainment. In recent years, an uneven yet growing body of research has suggested that obesity is associated with poorer academic performance beginning as early as kindergarten. Studies have variously found that obese students, especially 
girls, tend to have lower test scores than their slimmer peers, are more likely to be held back a grade and are less likely to go on to school and college.

Overweight and obesity receive great interest in psychosocial research. Special attention is given to the psychosocial strain that may result from weight status. Consequently, there is a wide range of psychosocial impairment and problems. There are social discrimination and teasing experience, emotional problems (anxieties, depression, and loneliness), school and functional restrictions and effects on the quality of life.

\section{JUSTIFICATION OF THE STUDY}

According to the World Health Organization, childhood obesity is already an epidemic in the developed world and is on the rise in developing countries. Obese children frequently suffer from depression, adjustment problems, low self esteem and related problems. Overweight children develop negative self-images, which can continue into adult years. Obesity can affect aspects of health and behaviour such as social adjustment, emotional adjustment, activity engagement, and goal direction.

\section{OBJECTIVES}

1. To identify obesity among children between 10 to 15 years by using anthropometric measurements.

2. To study the dietary and physical activity pattern of obese children and non-obese children.

3. To assess the different dimensions of adjustment of obese and non-obese children.

4. To find out the influence of BMI on the different dimensions of adjustment of obese and non-obese children.

5. To find out if there is any relationship between the different dimensions of adjustment with BMI of obese and non-obese children.

6. To find out whether different dimensions of adjustment of obese and non-obese children can be predicted by their BMI.

7. To find out whether adjustment of obese and non obese children can be predicted by life style (dietary and physical activity) pattern.

\section{METHOD}

Hypotheses

1. BMI has significant influence on the different dimensions of adjustment of obese and non-obese children.

2. There is significant relationship between BMI and the different dimensions of adjustment of obese and non-obese children.

3. Different dimension of adjustment of obese and non-obese children can be predicted by their BMI.

4. Adjustment of obese and non obese children can be predicted by life style (dietary and physical activity) pattern. 


\section{Sample selection and composition}

The present study has been conducted to find out the impact of obesity on social, emotional and educational adjustment of school going children in Kolkata. 100 sample were collected by stratified random sampling, out of which 50 were non-obese and obese boys, 50 were non-obese and obese girls belonging to the age range of 10 to 15 years.

The sample comprises of boys and girls studying in reputed Bengali and English medium (W.B. Madhyamik, ICSE and CBSE) schools of Kolkata.

BMI calculation has been done to measure the level of obesity.

\section{Tools used}

Adjustment Inventory For School Students (AISS) by Sinha and Singh, (2007): The inventory seeks to segregate well adjusted school student from poorly adjusted students in the three areas of adjustment-1) Emotional, 2) Social and 3) Educational. The inventory consisted of 60 items, 20 items in each area of adjustment. The test-retest reliability for emotional (0.96), social (0.90) and educational (0.93) and the validity is 0.51 . This is the 5 point scale: Excellent, Good, Average, Unsatisfactory and Very unsatisfactory.

\section{General Information Schedule:}

The information schedule consists of 42 questions on personal information, dietary and physical activity pattern, etc.

\section{Statistical Analysis}

The scores for each questionnaire were tabulated separately. Frequencies and percentages were calculated. Mean and standard deviation were found out for the two groups on basis of gender and type of obesity. Finally, the data were statistically treated to verify the hypotheses of the study by applying ANOVA, Correlation and Regression.

\section{RESULTS AND DISCUSSION}

Table no 1 Frequency Distribution of sample according to Gender and Level of Obesity

\begin{tabular}{|l|c|c|}
\hline Level of Obesity & Boys & Girls \\
\hline Under weight & - & - \\
\hline Normal weight & 25 & 25 \\
\hline Overweight & 12 & 12 \\
\hline Grade I obese & 12 & 8 \\
\hline Grade II obese & 1 & 5 \\
\hline Grade III obese & - & - \\
\hline
\end{tabular}


Table no 1 indicates that boys and girls ratio is same for normal weight and overweight children but in case of grade I obesity boys ratio are higher than girls and in case of grade II obesity girls ratio are higher than boys. Mahajan BP et al. (2011) and Jalila EA (2012) support this finding.

Table no 2 Dietary and Eating pattern of obese and non-obese children

\begin{tabular}{|l|c|c|}
\hline Dietary Pattern & Obese & Non-obese \\
\hline Like spicy food & 45 & 5 \\
\hline Like Junk food & 38 & 12 \\
\hline Like Homemade food & 1 & 49 \\
\hline Preference of Sweet & 36 & 14 \\
\hline Like fried food & 49 & 1 \\
\hline Eating Pattern & & 45 \\
\hline Normal & 23 & 5 \\
\hline Over eating & 27 & - \\
\hline Serious eating disorder & - & \\
\hline
\end{tabular}

Table no 2 shows that most of the obese children prefer spicy, junk food, fried foods and sweets whereas non-obese children prefer homemade foods. It also indicates that most of the obese child ren have over eating pattern where as non-obese children had normal eating pattern.

Table no 3 Mean and S.D. scores of Social, Emotional and Educational Adjustment

\begin{tabular}{|c|c|c|c|c|c|c|c|c|}
\hline \multirow[b]{3}{*}{ Dimensions of Adjustment } & \multicolumn{4}{|l|}{ Boys } & \multicolumn{4}{|l|}{ Girls } \\
\hline & \multicolumn{2}{|l|}{ Obese } & \multicolumn{2}{|c|}{ Non-obese } & \multicolumn{2}{|l|}{ Obese } & \multicolumn{2}{|c|}{ Non-obese } \\
\hline & Mean & S.D & Mean & S.D & Mean & S.D & Mean & S.D \\
\hline Emotional & 10.80 & 2.33 & 4.64 & 1.25 & 10.64 & 2.38 & 4.64 & 1.25 \\
\hline Social & 10.84 & 2.01 & 4.36 & 1.38 & 10.08 & 2.08 & 4.36 & 1.38 \\
\hline Educational & 10.60 & 2.02 & 4.64 & 1.29 & 10.64 & 1.39 & 4.64 & 1.29 \\
\hline
\end{tabular}

Table no 3 indicates that the mean scores of different dimensions of adjustment are higher amon g obese boys. Similarly, the mean scores of different dimensions of adjustment of obese girls are higher than non-obese girls. Higher mean scores indicate lower adjustment level. 
Table no 4 Percentage Distribution of the sample according to the different levels of adjustme nt with BMI (levels of obesity)

\begin{tabular}{|l|c|c|c|c|c|}
\hline \multicolumn{1}{|c|}{ Children } & \multicolumn{5}{c|}{ Adjustment } \\
\hline Level of obesity & Excellent & Good & Average & Unsatisfactory & Very unsatisfactory \\
\hline Under weight & - & - & - & - & - \\
\hline Normal weight & - & $34 \%$ & $66 \%$ & - & $2 \%$ \\
\hline Overweight & - & - & - & $46 \%$ & $40 \%$ \\
\hline Grade I obese & - & - & - & - & $10 \%$ \\
\hline Grade II obese & - & - & - & $2 \%$ & - \\
\hline Grade III obese & - & - & - & - & - \\
\hline
\end{tabular}

Table no 4 shows that most of the normal weight children have average level of adjustment, most of the overweight children have unsatisfactory level, most of the grade I and grade II obese children have very unsatisfactory level of adjustment.

Table no 5: One-way ANOVA of different dimensions of adjustment with respect to BMI

\begin{tabular}{|l|l|c|c|c|c|c|}
\hline \multicolumn{2}{|c|}{} & $\begin{array}{c}\text { Sum of Squ } \\
\text { ares }\end{array}$ & df & $\begin{array}{c}\text { Mean Squar } \\
\text { e }\end{array}$ & F & Sig. \\
\hline \multirow{4}{*}{ Emotional } & Between Groups & 1017.023 & 3 & 339.008 & 193.30 & .000 \\
\cline { 2 - 7 } & Within Groups & 168.367 & 96 & 1.754 & & \\
\cline { 2 - 7 } & Total & 1185.390 & 99 & & & \\
\hline \multirow{5}{*}{ Social } & Between Groups & 910.637 & 3 & 303.546 & 138.01 & .000 \\
\cline { 2 - 7 } & Within Groups & 211.153 & 96 & 2.200 & & \\
\cline { 2 - 7 } & Total & 1121.790 & 99 & & & \\
\hline \multirow{3}{*}{ Educational } & Between Groups & 940.315 & 3 & 313.438 & 181.93 & .000 \\
\cline { 2 - 7 } & Within Groups & 165.395 & 96 & 1.723 & & \\
\cline { 2 - 7 } & Total & 1105.710 & 99 & & & \\
\hline
\end{tabular}

Table no 5 suggests that the influence of BMI on the different dimensions of adjustment has been found to be significant at 0.01 level. There is a significant difference between obese and nonobese children with respect to BMI. Thus the hypothesis no 1 is accepted. The results indicate that independent variable (BMI) is an important source in causing variation in the dependent variables (emotional, social and educational adjustment). Lindsay C. Daniel (2011) supports this finding. 
Table no 6 Correlation between different dimensions of adjustment with BMI

\begin{tabular}{|c|c|c|c|c|c|}
\hline & & Emotional & Social & Educational & BMI \\
\hline \multirow[t]{3}{*}{ Emotional } & Pearson Correlation & 1 & $.914^{* *}$ & $.907^{* *}$ & $.908^{* *}$ \\
\hline & Sig. (2-tailed) & & .000 & .000 & .000 \\
\hline & $\mathrm{N}$ & 100 & 100 & 100 & 100 \\
\hline \multirow[t]{3}{*}{ Social } & Pearson Correlation & $.914^{* *}$ & 1 & $.925^{* *}$ & $.882^{* *}$ \\
\hline & Sig. (2-tailed) & .000 & & .000 & .000 \\
\hline & $\mathrm{N}$ & 100 & 100 & 100 & 100 \\
\hline \multirow[t]{3}{*}{ Educational } & Pearson Correlation & $.907^{* *}$ & $.925^{* *}$ & 1 & $.901^{* *}$ \\
\hline & Sig. (2-tailed) & .000 & .000 & & .000 \\
\hline & $\mathrm{N}$ & 100 & 100 & 100 & 100 \\
\hline \multirow[t]{3}{*}{ BMI } & Pearson Correlation & $.908^{* *}$ & $.882^{* *}$ & $.901^{* *}$ & 1 \\
\hline & Sig. (2-tailed) & .000 & .000 & .000 & \\
\hline & $\mathrm{N}$ & 100 & 100 & 100 & 100 \\
\hline
\end{tabular}

Table no 6 indicates that the different dimensions of adjustment are positively and significantly correlated with BMI. Higher score in adjustment scale denotes lower level of adjustment. Thus when BMI increases the score of adjustment increases which means adjustment level is low. So hypothesis no 2 is accepted.

Table No-7: Regression Coefficient between different dimensions of Adjustment with BMI

\begin{tabular}{|c|c|c|c|c|c|c|c|c|}
\hline Adjustment & $\begin{array}{l}\text { Regression } \\
\text { Coefficient }\end{array}$ & $\begin{array}{c}\text { Standard } \\
\text { error }\end{array}$ & $\beta$ & $\mathbf{R}$ & $\mathbf{R}^{2}$ & df & $\mathbf{F}$ & Sig. \\
\hline Emotional & .908 & .029 & .908 & .908 & .824 & $1, \quad 98$ & 459.75 & .00 \\
\hline Social & .882 & .032 & .882 & .882 & .778 & $1, \quad 98$ & 343.81 & .00 \\
\hline Educational & .901 & .029 & .901 & .901 & .811 & $1, \quad 98$ & 421.04 & .00 \\
\hline
\end{tabular}

**Significant at 0.01 level 
Results of regression analysis with BMI and the different dimensions of adjustment as dependent variable for the entire sample are presented in Table no-7. It shows that for the different dimensions of adjustment the $\mathrm{F}$ value is significantly predicted by the predictor- BMI. This is evident from the significant $F$ values. The overall $R^{2}$ values are high. The highest $R^{2}$ value reported is for emotional adjustment. It is .824 indicating that $82.4 \%$ of the variance in the entire sample on dimensions of emotional adjustment can be accounted by BMI. Thus the hypothesis no 3 is accepted.

Table no 8: Regression Coefficient between Adjustments with Lifestyle pattern

\begin{tabular}{|c|c|c|c|c|c|c|c|c|c|}
\hline $\begin{array}{c}\text { Lifestyle } \\
\text { pattern }\end{array}$ & $\begin{array}{l}\text { Regression } \\
\text { Coefficient }\end{array}$ & $\begin{array}{c}\text { Standard } \\
\text { error }\end{array}$ & $\beta$ & $\mathbf{R}$ & $\mathbf{R}^{2}$ & & & $\mathbf{F}$ & Sig. \\
\hline $\begin{array}{l}\text { Preferred } \\
\text { sweets }\end{array}$ & -.290 & .477 & -.290 & .290 & .084 & 1 , & 98 & 8.966 & .00 \\
\hline $\begin{array}{l}\text { Like fried } \\
\text { foods }\end{array}$ & -.411 & .368 & -.411 & .411 & .169 & 1 , & 98 & 67.54 & .00 \\
\hline $\begin{array}{c}\text { Exercise } \\
\text { Regularly }\end{array}$ & .639 & .389 & .639 & .639 & .408 & 1 , & 98 & 67.54 & .00 \\
\hline
\end{tabular}

**Significant at 0.01 level

Results of regression analysis with Lifestyle pattern and adjustment as dependent variable for the entire sample are presented in Table no-8. It shows that for dimensions of adjustment the F value is significantly predicted by the predictor- Lifestyle pattern. This is evident from the significant $\mathrm{F}$ values. The overall $\mathrm{R}^{2}$ values are low. The highest $\mathrm{R}^{2}$ value reported is for Exercise regularly. It is .408 indicating that only $40.8 \%$ of the variance in the entire sample on adjustment can be accounted by Lifestyle pattern. Thus the hypothesis no 4 is accepted.

\section{DISCUSSION}

Obese children prefer sweets, spicy, junk and fried foods, whereas non-obese children prefer homemade foods. Consumption of excessive junk foods and fried foods lead to weight gain and which may further lead to obesity. Obese children have habits of over eating. Over eating habits may lead to obesity in children. Most of the obese children do not exercise regularly.

The mean values of the different dimensions of adjustment of obese children are higher than non-obese children which means that non-obese children are better emotionally, socially and educationally adjusted as higher score in adjustment denotes lower adjustment level. The influence of BMI in different dimensions of adjustment (emotional, social and educational) is significant.

Obese children have unsatisfactory adjustment level whereas non-obese children have good adjustment level. The influence of BMI on the different dimensions of adjustment has been found to be significant for obese and non-obese children. There has been a significant positive 
correlation between the different dimensions of adjustment scores with BMI of entire sample which means lower level of adjustment. Different dimensions of adjustment of obese and nonobese children can be predicted by their BMI. Also, adjustment of obese and non obese children can be predicted by the life style pattern.

\section{CONCLUSION}

After analyzing the data we have found that there has been a significant difference in adjustment level between obese and non-obese children. Non-obese children have good adjustment level whereas obese children have very unsatisfactory level of adjustment. Girls have higher level of obesity because they have less physical and outdoor activities compare to boys. The influence of BMI on adjustment of the entire sample has been found to be significant. The lifestyle pattern has significant influence on social, emotional and educational adjustment.

To avoid obesity in children parents should emphasis on healthy eating, physical activity, etc. Childhood obesity is hampering the mental health of children. Hence, there are several opportunities to overcome the obesity epidemic, although it will certainly not be easy unless all relevant members like parents, teachers, doctors, psychologists and whole community will work together towards a common goal. Media and public health campaign have an important role to spread awareness about obesity prevention programmes. Otherwise overall development will not be possible because children are the citizen of tomorrow.

\section{IMPLICATION OF THE STUDY}

1. Main focus of preventive programmes should be directed towards prevention of obesity throughout childhood and adolescence.

2. Public health campaign directed towards life style changes in the family or society as a whole.

3. Most obesity related disorders can be prevented or effectively managed if picked up early in life.

4. Benefits of healthy eating, increased physical activity and reduction in sedentary activities have to be inculcated from early age.

5. Health authorities and media have an important role to play to spread awareness about obesity prevention programmes.

\section{REFERENCES}

Baum, C. G., \& Forehand, R. (1984). Social factors associated with adolescent obesity. Journal o f Pediatric Psychology, 9, 293-302.

Faith M. S., Leone M. A., Ayers T. S., Moonseong H., Pietrobelli A. (2002). Weight criticism du ring physical activity, coping skills and reported physical activity in children. Pediatric; 110, e23.

Frey K. S., Hirschstein M. K., Snell J. L., Edstrom L. V., MacKenzie E. P., Broderick C. J. (2005 ). Reducing playground bullying and supporting beliefs: An experimental trial of the step s to respect program. Developmental Psychology; 41, 479-490. 
Jalila E. A., Pierre T. (2012). Gender Obesity Inequities Are Huge but Differ Greatly According to Environment and Socio Economics in a North African Setting: A National Cross Sectional Study in Tunisia. Public Library of Science, 7(10):e48153. doi:10.1371/journal.pone.0048153.

Lerner, R. M. (1973). The development of personal space schemata toward body build. Journal o f Psychology. 84, 229-235.

Lerner, R. M., \& Pool, K. B. (1972). Body-build stereotypes: A cross-cultural comparison. Psych ological Reports, 31, 527-532.

Lhila, S. (2015, July). Childhood Obesity-A Silent Epidemic. Pratidin Health Guide, 53.

Lindsay, C. D. (2011). The Psychological Implications of Obesity in Adolescent High School Students. Pediatrics. 17(3).

Mahajan, P. B., Purty., A.J., Singh, Z., Cherian, J., Ntesan, M.,Arepally, S., and Senthilvel, V. (2011). Study of Childhood ObesityAmong School children Age 6 to 12 Years in Union Territory of Puducherry. Indian Journal of Community Medicine: Official Publication of Indian Association of Preventive and Social Medicine, 36(1), 45-50. doi:10.4103/09700218.80793

Storch E. A., Ledley D. (2004). Peer victimization and psychosocial adjustment in children: curr ent knowledge and future directions. Clinical Pediatrics; 44, 29-38.

Strauss C. C., Smith K., Frame, C , \& Forehand R. (2004). Personal and interpersonal characteris tics associated with childhood obesity. Journal of Pediatric Psychology, 10, 337-343. 